\title{
Manchester's Cyberstalked 18-30s: Factors Affecting Cyberstalking.
}

\author{
M. J. Berry \\ Royal College of Surgeons, Dublin, Ireland. \\ RCSI Institute of Leadership, Reservoir House, Sandyford, Dublin, Ireland
}

\author{
S. L. Bainbridge \\ Psychology Graduate \\ Manchester Metropolitan University
}

\begin{abstract}
Purpose For many people modern life is experienced through an 'online' platform. The purpose of this study was to investigate the frequency of cyberstalking among Manchester's cosmopolitan 18-30s along with the relationships between online activities, demographic variables and occurrences of cyberstalking. Methodology We adopted a face-to-face request for completion of a revised Bocij [2003] questionnaire with a 96\% response rate. One hundred volunteer Internet users aged 18-30 (65 students, 35 non-students) completed a survey on their suspected cyberstalking experiences. Findings The expected prevalence rate of $10-20 \%$ was exceeded with an actual rate of $20-34 \%$ of participants having reported cyberstalking experiences. Contrary to offline stalking victimisation, males were just as likely to be cyberstalked as females. There were, however, gender differences in the way that victims responded. Almost half of the sample reported inappropriate or obscene messages. All forms of messaging were frequently reported, as well as damage to data or equipment. Some aspects of Internet use were associated with victimisation but young people were at possible risk regardless of demographic variables. Limitation: The size of the sample, the unexpected female to male ratio and the higher than expected ethnic minority. Originality/Value A high level of cyberstalking was identified in the 18-30 group. Many victims failed to recognise their experiences as a case of cyberstalking and as such there is a need for the authorities to increase awareness, provide support and identify likely perpetrators based upon the first specific cyberstalking study on 18-30 year olds in the UK. 248 words
\end{abstract}

Keywords: Online harassment, cyberstalking, Manchester's 18-30s, gender, victims.

\section{INTRODUCTION}

Bocij [1] defined cyberstalking as the use of Information and Communications Technology (ICT) to harass individuals, group of individuals or organisations. It includes persistent, unwanted contact of an offensive/threatening nature, monitoring data, damaging data or equipment, damaging a reputation and encouraging others to join in. Sheridan and Grant [2] included posting hostile information about victims online; using social networking sites to harass; subscribing to services or products in the victim's name; hacking victim's personal accounts; online identity theft; impersonating the victim online; and sending the victim computer viruses.

Until recently, cyberstalking compared to stalking appears to have been of less public and academic interest. However 'offline' stalking has been researched for many years. For example, Pathe and Mullen [3] interviewed 100 stalking victims of whom $80 \%$ reported hypervigilance/panic attacks, $75 \%$ sleep disorders, $50 \%$ appetite disorders and $25 \%$ had 
considered or attempted suicide. Some victims curbed their social activities, withdrew from education/work, and even relocated in an attempt to escape attention.

Tjaden and Thoennes [4] interviewed 8,000 males and 8,000 females classifying 640 females (8\%) and 160 males (2\%) as stalking victims. A meta-analysis of almost 70,000 participants [5] suggested a much higher prevalence in the U.S. While the British Crime Survey [6] reported 1,178 (12\%) of 9,988 participants had been stalked in their life and 290 (3\%) had been stalked in the past year with females twice as likely to be stalked as males. Dressing, Kuehner and Gass' [7] survey of 679 German residents found that $78(11 \%)$ had been stalked of whom $87 \%$ were females, and $11(1.6 \%)$ victims were currently being stalked. The Australian Bureau of Statistics [8] estimated that 1,613,400 (19\%) females and 663,800 (8\%) males had been stalked in their lifetime, highlighting a lifetime threat.

Mullen, Pathe and Purcell [9] proposed the following victim typology, a) prior intimates, b) estranged family and friends, c) casual acquaintances, d) workplace contacts, e) professional contacts, g) public figures, h) secondary victims, i) strangers and j) unknowns. Some individuals experience sequential or even concurrent stalking. However, not all claims of stalking victimisation are genuine. False stalking victims may be delusional due to mental illness, hypersensitive because individuals have been stalked before, factitious, malingering, attempting to evade criminal prosecution or attempting gain financially. Nevertheless, stalking has been generally underreported to authorities [7].

Various studies have reported broad stalking prevalence rates $[10,11,8]$. Baum, Catalano, Rand and Rose [12] reported that $26 \%$ of those stalked in the 2006 USA National Crime Victimisation Survey received unwanted emails from their stalker. Increasing Internet use, with more on-line personal data available [13], was likely to enable more people to pursue relationships or their desire for revenge. Cavezza and McEwan [14] reported that most of the major studies on cyberstalking produced prevalence figures from $1 \%$ to $41 \%$ based on student populations, although these differences are likely to be due to methodological differences. Currently the extent of cyberstalking in the UK is comparatively unknown.

Grabosky [15] argued that cybercrime should be conceptualised like any other crime because technology is utilised to support familiar causes. However, Bocij and MacFarlane [16] argued that it did not overlap with offline stalking and constituted a distinct social problem. Accordingly, cyberstalkers harass numerous victims simultaneously rather than just one, and demonstrate exploitative rather than obsessive motivation. Sheridan and Grant [2], concluded cyberstalking is not fundamentally different from offline stalking whereas more recently Cavezza and McEwan [14] argued there are few differences between them. Dreßing, Bailer, Anders, Wagner and Gallas [17] argued that cyber stalking victims appear similar to offline stalking victims.

Individuals engaging in risky online activities, such as posting personal information and pictures, participating in open chatrooms and visiting pornographic websites, were more likely to become victims of cyberstalking [18]. D'Ovidio and Doyle [19] reported 80\% cyberstalkers perpetrators were male with a mean age of 24 with a quarter under 16 . We speculated within the psychosocial model that cyberstalking is relatively common, particularly among $18-30 \mathrm{~s}$ who are comfortable in the social networking era and they are more likely to engage in risky behaviour and as such they are most likely to be at risk.

The Crime Survey for England and Wales [20], reported for 2015/16, some 4.6\% of women and $2.7 \%$ of men, aged 16-59, were victims. It also indicated one in ten men and one in five women 
will be affected by stalking in their lifetime, and approximately 14,000 calls were made to The National Stalking Helpline. In the year to June 2016, the police recorded 4,168 stalking offences with an increasing rate from the record $13,000^{+}$telephone calls in 2014-15 [20].

Bocij [21] devised an 11-item measure of cyberstalking and recruited 169 participants via the Internet; 37 (22\%) were identified as victims of cyberstalking according to Bocij and MacFarlane's [22] definition of two or more on-line reported incidents with the same perpetrator(s) that caused them distress. The use of snowball sampling was a limitation in Bocij's study, which could account for the high prevalence despite a strict operational definition.

Finn [23] found that $34(10 \%)$ of 339 USA undergraduates had been harassed via email or instant messaging, 23 victims (68\%) reported the harassment but only $12(35 \%)$ felt that reporting it was worthwhile. Some 13\% of victims were organisational targets (a group often ignored by researchers), 52\% were female and 35\% male. The majority of offenders (92\%) used one method of online harassment namely: email (79\%), instant messages (13\%), chat rooms (8\%), message boards (4\%), web sites (2\%) and newsgroups and $1 \%$ fake user profile. Alexy, Burgess, Baker and Smoyak (24) identified 28 (4\%) of their 756 USA undergraduates had been cyberstalked. Victims were more likely to be male and less likely to report the cyberstalking. They reported that classmates or ex-intimates were the most likely victims, while males were more often victims of cyberstalking and females were more likely to be victims of off-line stalking. Cyberstalking victims were more likely to receive threats while cyberstalkers were more likely to threaten suicide. Those who experienced cyberstalking were also likely to experience off-line harassment by stalkers.

Sheridan and Grant [2] classified 1,051 self-identified stalking victims into: 42 (4\%) victims of 'purely online' offending; the 'cross-over' group (51,5\%) who had initially internet stalked before moving on to real world stalking; 401 (39\%) originally stalked off-line but harassed via the Internet as part of the victimisation experience and the reality stalked victims $(545,52 \%)$. Internet stalking was carried out more often by acquaintances and strangers than by expartners with little difference between on and off-line stalking.

Maple, Short and Brown [25], online survey of 324 participants (34\% male), 92\% reported experiencing cyber harassment (including cyberstalking). Consistent with previous studies of non-student populations, they identified $52 \%$ having had some intimate relationship with the stalker, $28 \%$ as a former acquaintance but only a fifth had little relationship with the perpetrator. Respondents were classified as: 'online only' victims (20\%) while 4\% moved from 'online to offline' harassment, most (76\%) were 'mixed' where perpetrators and victims first met in a real-world setting and then harassed in a virtual world contrasting Sheridan and Grant [2] study. McEwan, Mullen, Mackenzie and Ogloff, [26] argued cyberstalkers were less likely to be violent to ex-partners than stalkers.

Nobles, Reyns, Fox, and Fisher [27] compared 1,237 (81\%) stalking victims who had not experienced cyberstalking with 296 (19\%) who had. They argued cyberstalking was a 'subset' of stalking with perpetrators taking advantage of the Internet whereby victims were likely to be white younger males with significantly higher income and education compared to off-line stalking victims. This suggested that younger, better educated and wealthy Internet sophisticated individuals were possibly overrepresented cyberstalking offenders and this was part of the basis of our study that a similar presentation would occur in victims hence the study of 18-30 year olds. 
Cavezza and McEwan [14], in one of the first match pairing studies compared 36 Australian cyberstalking offenders with a matched sample of off-line stalkers. They found cyberstalkers were more likely to be ex-intimate partners $(\mathrm{p}=.02)$ and less likely to approach their victims $(\mathrm{p}$ $<.05)$ than off-line stalkers. The majority of cyberstalkers also used off-line stalking tactics. Cyberstalkers with different motivations used the Internet in different ways.

Only 36 (13\%) of their [14] 271 referred stalking cases were cyberstalkers; 94\% of whom were males with an average age of $36.7(\sigma=11.0)$ compared to $36.8(\sigma=11.2)$ with off-line stalkers. Cyberstalkers may be in the minority because they are less likely to be criminalised. The majority (72\%) were referred from Probation Service or the courts with only one (3\%) self-referred. We were fascinated that five $(14 \%)$ of their cyberstalking sample were pensioners. (The first author refers to these as "silver stalkers"). Cyberstalkers and off-line stalkers did not differ in stalking duration (median duration for cyberstalkers $=36$ weeks, offline stalkers $=37$ weeks). Both targeted women but cyberstalkers were more likely to be subject to a restraining order than 'offliners' $(\mathrm{p}=<.05)$. Whilst $70 \%$ of cyberstalkers breach their Restraint Orders, they were less likely to approach victims $(\mathrm{p}=<.05)$.

Cavezza and McEwan [14] classified their 36 cyberstalkers as 27 (75\%) rejected; five (14\%) resentful; two (5\%) intimacy seekers; one (3\%) incompetent suitor (3\%) and one (3\%) as predatory. They reported that cyberstalkers used: telephone calls $21(58 \%)$, letters/faxes 7 (19\%), SMS text messages 14 (39\%); sent unsolicited materials 10 (28\%); displayed approach behaviours 20 (56\%); spied 10 (28\%); followed victims 6 (17\%); accosted victims 8 (22\%); stalked by proxy 5 (14\%); entered victims' homes 9 (25\%); made explicit threats 14 (39\%); violence $2(5 \%)$; damage to property $2(5 \%)$ although the actions were not mutually exclusive list. $27(77 \%)$ had received Restraining Orders.

Cavezza and McEwan [14] reported cyberstalkers were significantly more likely to be exintimates than off-line stalkers, unlike earlier studies of cyberstalking where ex-intimates accounted for approximately $50 \%$ of cases with approximately $20-30 \%$ of stalking cases involve physical violence [28] usually by ex-intimates and studies suggest that violence occurs in many such cases [29]. However as cyberstalkers are less likely to approach victims, they have a lower incidence of physical violence. Cyberstalkers were as likely as off-line stalkers to have multiple victims during the current stalking episode and were more likely to have stalked different victims than that of the index episode.

Suler [30] coined the term 'online disinhibition effect' to describe the phenomenon of individual self-disclosing or verbalising more than they would normally express. The Internet is easily accessible and individuals may be more inclined to behave deviantly online because of disinhibition and depersonalisation [9]. It is easy for behaviour to escalate in cyberspace and what seems acceptable to one person might seem completely inappropriate to another. Currently there are no 'Internet Police' in the U.K. as there are no specific laws against cyberstalking. It is difficult to investigate because perpetrator(s) and victim(s) can reside in different jurisdictions [31], and legal definitions and sentencing vary. Surfing the Internet allows anonymity, invisibility, fluctuating levels of communication, assigning images to another person, dissociative imagination (where everyday rules and norms do not seem to apply). Hiding one's true status and authority seems to enhance this disinhibition ('catfishing'). Ménard and Pincus [32] suggested the Internet may empower some individuals to stalk, who would not otherwise.

Berry [33] argued that some individuals are more vulnerable such as members of the Deaf community who are prone to misinterpret some internet communications because for many 
who use British Sign Language, English is a second language, in addition to their perceived vulnerability by the Hearing Society. Paullet, Rota and Swan [34] revised the work of Bocij [21]; identifying 40 (13\%) of 302 USA students as cyberstalking victims; females were twice as likely to be cyberstalked compared to males.

Although stalking figures fluctuate according to sample size, sampling method and stringency of the definition employed, stalking is relatively common in many parts of the world and especially among females. Most victims are aged 18-24 years old [6,8]. To the writers' knowledge, ours is the first studies of its kind to specifically sample 18-30 year old UK residents.

\section{METHODOLOGY}

It was hypothesised that $10-20 \%$ of participants would be identified as cyberstalked victims, with no age, employment, ethnicity or gender differences based on two-tailed tests as the literature indicated ambiguous results. Having less Internet experience, spending more time online and engaging in a wider scope of online activities were expected to present as cyberstalking risk factors.

The frequency of cyberstalking was examined using a partial replication of Bocij's 11-item measure. Unlike his study, our survey was paper-based and conducted in person. There was a focus on young people as a high-risk group [1,23] and a comparison between students and non-students. As a highly populous metropolitan city of half million citizens, Manchester allowed for a diverse sample. Manchester is a major industrial city in the North West of England with three universities and two world famous soccer clubs and a great music scene.

Cyberstalking victims were identified as those who reported two or more distressing, ICTbased experiences with the same perpetrator(s) as per their definition [22]. Internet use and demographic details were examined to identify factors affecting possible cyberstalking victimisation. Variables of interest were age, gender, sexual orientation, ethnicity, and employment. Along with the longevity, frequency and duration of Internet use and online activities as well as perpetrator identity, reporting patterns and identifying the experiences as a form of stalking.

\section{Instrument}

The survey consisted of 20 questions in four sections, largely multiple choice with some optional, open ended questions. It had a high Flesch Score [35] of 60 and took 5-10 minutes to complete. The terms 'cyberstalking' and 'victim' were purposely avoided to reduce possible cueing of replies. Section 1 examined the longevity, frequency and duration of participants' Internet use and typical online activities. Section 2 was a 12 -item partial replication of the items developed by Bocij [21], used with his agreement. Items were reworded to specify relying on ICT and causing distress. Items 1, 2 and 3 referred to the experience of receiving threatening or abusive messages perpetrated via email, instant messaging and chatrooms. We condensed these and implemented an additional question regarding the mediums used. Messages could also be a) 'excessively affectionate', b) 'needy or demanding' and c) 'inappropriate or obscene', so three items were added. Section 3 collected details about any experiences reported in section 2. Websites including social networking, photo/video sharing, blogging, Q \& A websites, dating and gaming websites were added to the list. Other items addressed response and reporting patterns, the victim/perpetrator relationship and harassment longevity. Participants were asked if they considered their experiences as a form of 'stalking' (the term cyberstalking was not used). Section 4, collected data on age, gender, sexual orientation, ethnicity and employment. 


\section{PROCEDURE}

A convenience sample of a hundred 18-30 year-olds participants were recruited from approximately 10,000 18-30 year old residents in the catchment area of Rusholme and the City Centre [36], representing a 1\% sampling rate. Potential participants were approached in libraries, ICT rooms and refectories on university campuses and, with managerial permission and staff supervision, selected nearby public libraries, Internet cafes and coffee shops with WiFi connection. Participants were given a consent form, a brief summary of the study, a questionnaire, a debriefing, the researchers' contact details and a list of Internet safety organisations and victim support groups.

\section{RESULTS}

A hundred volunteers (65 students, 35 non-students) completed the survey. The response rate was $96 \%$ as four individuals declined to participate. Two participants completed the survey incorrectly and were replaced resulting in 66 females and 34 males; 91\% were 'straight', 6\% gay or lesbian, $2 \%$ bisexual and one $(1 \%)$ transgender; indicating a reasonable representative sample. Sixty-eight percent were White, 17\% Asian, 7\% Black, 5\% Chinese and 3\% Mixed Ethnicity. Sixty-five percent were students, 14\% professionals, 11\% manual workers, 3\% managers, $2 \%$ clerical workers, $2 \%$ homemakers, $2 \%$ unemployed and $1 \%$ self-employed.

Twenty participants were identified as victims of cyberstalking as per Bocij and MacFarlane [22], reporting two or more distressing experiences perpetrated by the same person(s). An additional 55 answered 'yes' to one or more cyberstalking items but did not meet the strict criteria because they could not be sure their experiences involved the same perpetrator, they experienced different perpetrators or they experienced an isolated incident. Twenty-five participants answered 'no' to all cyberstalking items. The writer(s) identified four cumulative groups namely: Group 1 strict victims (20), according to Bocij and McFarlane's 2003 definition; Group 2 (14) those who may have been victims (34) but did not know the perpetrator's identity, Group 3 (28) included those whose various experiences had different perpetrators (62) and Group 4 (13) included those who experienced an isolated incident (75) and reported one-off event. Twenty five had nothing to report. The 100 participants were aged between 18-30 years old $(\bar{x}=22.5, \sigma=3.1)$ with the 20 strict victims followed a similar pattern $(\bar{x}=22.7, \sigma=3.3)$. Table 1 summarises the levels of cyberstalking dependent on definition stringency. 
Table 1 - The occurrences of cyberstalking items

$\begin{array}{lcc}\text { Distressing experience } & \begin{array}{l}100 \\ \text { Respondents } \\ (\%)\end{array} & \begin{array}{l}20 \text { strict } \\ \text { Victims } \\ (\%)\end{array} \\ \text { Inappropriate or obscene messages } & 43 & \checkmark \\ \text { Damaging data or equipment } & 38 & 80 \\ \text { Needy or demanding messages } & 33 & 60 \\ \text { Excessively affectionate messages } & 29 & 65 \\ \text { Threatening or abusive messages } & 26 & 50 \\ \text { Accessing confidential information } & 19 & 65 \\ \text { Impersonation via an account } & 18 & 35 \\ \text { Spreading false information } & 13 & 30 \\ \text { Attempting to monitor your actions } & 8 & 35 \\ \text { Encouraging other users to harass you } & 5 & 15 \\ \end{array}$

All forms of messaging were reported, as well as damage to data or equipment. Participants reported 0-7 of the 12 cyberstalking items $(\bar{x}=2.4, \sigma=2.1)$ listed in the survey (table 1$)$ and 0-7 of the 11 mediums $(\bar{x}=1.6, \sigma=1.5)$, while 20 Strict victims reported $2-7$ items $(\bar{x}=4.6, \sigma=1.4)$ and 1-7 mediums $(\bar{x}=2.6, \sigma=1.3)$ see below.

$\begin{array}{lcc}\text { Table } 2 \text { - The mediums used to carry out cyberstalking (Groups 1-4) } \\ \text { Medium used } & 75 & 20 \\ & \text { Victims } & \text { Strict Victims } \\ \text { Social networking websites } & (\%) & (\%) \\ \text { Email } & 72 & 95 \\ \text { Instant messaging } & 65 & 80 \\ \text { Chatrooms } & 36 & 45 \\ \text { Forums } & 12 & 5 \\ \text { Photo/video sharing websites } & 8 & 5 \\ \text { Blogging websites } & 7 & 5 \\ \text { Dating websites } & 4 & 10 \\ \text { Gaming software } & 3 & 5 \\ \text { Question and Answer websites } & 3 & 5 \\ \end{array}$

Social networking websites were the most common means of online harassment. Cyberstalking items were perpetrated via 9 of the 11 aforementioned methods in table 2 but the majority was restricted to social networking websites, emails and instant messaging.

Of the 75 victims, $48 \%$ prevented communication via the Internet, $36 \%$ responded via the Internet; $25 \%$ took action in person and $37 \%$ did nothing compared to the 20 strict victims with $70 \%, 55 \%, 30 \%$ and $30 \%$ respectively for the same responses. Strict victims were more likely to have responded via ICT $\left(\mathrm{X}^{2}(\mathrm{df}=1, \mathrm{n}=100)=4.27, \mathrm{p}<0.05\right)$ or prevented further communication via ICT $\left(\mathrm{X}^{2}(\mathrm{df}=1, \mathrm{n}=100)=5.28, \mathrm{p}<0.05\right)$. Strict victims were more likely to be targeted by 'significant others' $\left(\mathrm{X}^{2}(\mathrm{df}=1, \mathrm{n}=100)=3.97, \mathrm{p}<0.05\right)$ or persons known through the Internet $\left(\mathrm{X}^{2}(\mathrm{df}=1, \mathrm{n}=100)=5.12, \mathrm{p}<0.05\right)$. Choosing numerous perpetrator identities could indicate joint affiliation between 'significant others' and individuals known through the Internet, or repeat victimisation.

Eight (40\%) of the 20 strict victims were cyberstalked for less than 7 days, seven (35\%) for 1-8 weeks, four $(20 \%)$ for $2-12$ months, and one $(5 \%)$ for more than 1 year. Most cyberstalking 
was resolved in a matter of days or weeks, but four (20\%) cases were viewed as acute and one (5\%) was viewed as chronic. Three strict victims (15\%) were currently being cyberstalked, a higher rate than would normally be expected. Sixteen (80\%) strict victims reported their abuse to family and friends, $10(50 \%)$ to university/work and $1(5 \%)$ each reported to an Internet Service Provider or safety organisation. None reported to the Police and three (15\%) didn't tell anyone. It is of some concerns that 7 (35\%) victims did not consider their experiences a form of cyber/stalking and $2(10 \%)$ were unsure, although $21 \%$ of 34 males and $20 \%$ of 66 females met the strict criteria. There was no significant difference of strict criteria by gender.

\section{Differences}

There were no significant gender differences in cyberstalking victimisation across groups (14). However, males were significantly more likely to experience somebody attempting to monitor their actions $\left(\mathrm{X}^{2}(\mathrm{df}=2, \mathrm{n}=100)=7.92, \mathrm{p}<0.05\right)$. Females were more likely to prevent further communication $\left(\mathrm{X}^{2}(\mathrm{df}=1, \mathrm{n}=75)=6.76, \mathrm{p}<0.01\right)$ and more inclined to try numerous responses. Males tended to ignore cyberstalking behaviours. Females were more likely to be targeted by a person known through the Internet $\left(X^{2}(\mathrm{df}=1, \mathrm{n}=75)=4.40, \mathrm{p}<0.05\right)$; only $9 \%(6)$ of the females' perpetrators were 'significant others', compared to $18 \%$ for males. Females were cyberstalked across a range of time periods but males were typically cyberstalked for 1-8 weeks and were less likely to report it, while females did. Six of 13 female victims (46\%) considered their experiences a form of stalking, while 6 of 7 male victims (86\%) did not.

Twenty percent (18) of 91 'straight' participants and 22\% (2) of nine LGBT participants met the strict criteria. Sixteen (24\%) of 68 'white' participants and four (13\%) 'Ethnic minority' participants met the strict criteria. 'Ethnic minority' participants were more likely to respond to internet or in person and less inclined to prevent further communication or do nothing. They were more likely to be targeted by family members and less likely to be targeted by acquaintances or friends. 'White' participants were cyberstalked for a range of time periods but 'ethnic minority' participants were typically cyberstalked for 1-8 weeks and told friends and family, or nobody.

Eleven $(17 \%)$ of 65 students and nine (26\%) of 35 non-students met the strict criteria. Students were significantly more likely to respond via ICT $\left(X^{2}(d f=1, n=75)=4.81, p<0.05\right)$ and non-students were more likely to be targeted by significant others or persons known through the Internet. Students were more likely to be targeted by acquaintances, friends, classmates, or strangers but resolved the situation quicker. Three of 11 students (27\%) and four of 9 (44\%) non-students considered their experiences a form of stalking and a worrying $13(65 \%)$ did not. There was a positive correlation between age and cyberstalking items reported $(\mathrm{r}=0.19$, $\mathrm{n}=100, \mathrm{p}<0.05)$. This was apparent among females $(\mathrm{r}=0.23, \mathrm{n}=66, \mathrm{p}<0.05)$ and students $(\mathrm{r}=0.21, \mathrm{n}=65, \mathrm{p}<0.05)$ but not males or non-students. It was strong among 'ethnic minority' participants $(\mathrm{r}=0.47, \mathrm{n}=32, \mathrm{p}=<0.01)$; but not for 'white' participants. There were no significant age differences in cyberstalking victimisation across groups 1-3.

Email and social networking websites were the most popular Internet uses for over $90 \%$ of the sample with 55\% using instant messaging. Around 20\% used forums and blogging websites, 5$10 \%$ used chat rooms and Q \& A websites. None of the Internet uses were particularly associated with victimisation, although all group 1 and group 2 victims used social networking sites. Participants reported 2-13 Internet uses $(\bar{x}=6.04, \sigma=1.9)$, while strict victims reported 310 Internet uses $(\bar{x}=5.9, \sigma=1.9)$. Cavezza and McEwan's (14) cyberstalkers used significantly more different types of communicative behaviours and stalking behaviours $(\bar{x}=4.39, \sigma=1.9)$ than off-line stalkers $(\bar{x}=3.13, \sigma=1.9 ; \mathrm{p}=.007)$ overall, with cyberstalkers using emails (64\%) and social networking sites (36\%); their rate was lower than ours. 
Twenty-five participants used the Internet less than 5 hours per week with $16 \%$ victimisation, 34 used it 5-15 hours per week with a 24\% victimisation and 41 participants used it more than 15 hours with a $20 \%$ victimisation. Across groups 1-4, the risk of victimisation was not related to the average amount of time spent online. Participants who spend 5-15 hours per week online were more likely to take action in person and less likely to prevent further communication or do nothing. They were more likely to be targeted by acquaintances, friends, classmates or colleagues, and less likely to be targeted by 'significant others', persons known through the Internet or strangers. The longest cases of cyberstalking involved victims who used the Internet for more than 15 hours per week. Victims who spend less than 5 hours per week online told friends and family or nobody.

There was a positive correlation between Internet uses and cyberstalking items reported $(\mathrm{r}=0.18, \mathrm{n}=100, \mathrm{p}<0.05)$, amongst 'white' participants $(\mathrm{r}=0.23, \mathrm{n}=68, \mathrm{p}<0.05)$, but not 'ethnic minority' participants, students or non-students. It was very strong among females $(\mathrm{r}=0.37$, $\mathrm{n}=66, \mathrm{p}<0.001$ ), but not among males; as there was a negative correlation between the number of Internet uses and cyberstalking items reported. There were no significant relationships between quantity of Internet usage in cyberstalking victimisation across groups 1-4. Participants with 5-15 years experience were more inclined to try numerous responses to cyberstalking behaviour. The longer participants had been using the Internet, the more likely they were to be targeted by unknown persons. Participants with more than 15 years of experience had only been targeted by persons known through the Internet and unknown persons. Those who were either relatively new or very accustomed to the Internet were cyberstalked for longer periods of time and only told friends and family.

\section{DISCUSSION}

One of the many problems in earlier research is the issue of self selecting samples in various studies especially those conducted online; we felt that there were advantages in undertaking face to face contact with the participants. However one of the weaknesses of our study is that we are trying to indicate prevalence rates rate while using an opportunistic sample, nevertheless we would argue that the study raises useful questions and should be the basis for future studies especially as our study identified a frequency of cyberstalking among Manchester's 18-30s of at least 20\% and potentially 34\%, partly attributed to the use of social networking websites. Internet use was associated with victimisation, with the variety, longevity and frequency of use implicated. As predicted, males were just as likely to be cyberstalked as females. There was a non statistical trend for 'white' participants and nonstudents to appear high-risk. The comparative high percentage of ethnic minority respondents was due to the university being near Manchester's famous 'Curry Mile' and its high Asian population. (This was not originally anticipated).

Our 20\% figure is consistent with Bocij's [22] 22\% utilising the same definition of cyberstalking and a similar sample size. Spitzberg and Hoobler (5) utilised a definition of cyberstalking that included unrelated and isolated incidents, similar to the 'group 4' victimisation but their figure was 33\%, compared to our study's 75\%. The prevalence of cyberstalking may be higher among non-students, although it is not clear if this is consistent across the U.K. or is increasing worldwide over time. However, we, as have most researchers, concentrated on individual victims and have ignored organisation of which some $13 \%$ of victims were targeted organisations [22]. Targeting organisations, we feel will increase with the increase use of algorithms.

In many ways the messaging facilities on social networking websites are replacing emails. It was hypothesised that inexperienced Internet users would be vulnerable to online harassment, however the most experienced Internet users tended to report more cyberstalking. Although it 
can be argued that they may be more Internet experienced to be able to identify it. This could also account for the positive correlation between age and victimisation.

Our findings regarding ethnicity supports the findings of Finn [23] and WHOA [37]. We challenge the findings that females are more likely to be cyberstalked [34], and show how cyberstalking victimisation differs from offline stalking victimisation. The lack of gender differences may be linked to the different contexts in which cyberstalking arises. The majority of stalkers are prior-intimates or strangers, typically heterosexual males with an infatuation or obsession. According to the present study, cyberstalkers are usually acquaintances, family, or friends. This suggests that the perpetrators' motivation behind cyberstalking is less 'amorous' and more malicious, reducing the gender differences in perpetration and victimisation alike. Moreover, 'significant others' were identified as cyberstalkers by twice as many males as females. Considering the predominantly heterosexual sample, most amorous cyberstalkers were females! Hammond et al [38] reported 57\% female victims in their self identified 112 web linked volunteers' sample of (18-70 with a mean of 35 years old). They reported that young males were equally likely to be victimised although the perception of cyberstalking was the same irrespective of being cyber-stalked with strangers (highest group) and 'exs' the least likely perpetrators.

Whilst 18-30s are at risk of victimisation, they are prone to different kinds of cyberstalking. 'Ethnic minority' participants were less likely to be targeted by an acquaintance or friend and more likely to be targeted by a family member, perhaps reflecting different cultural norms. Females and non-students were more likely to be targeted by persons known through the Internet, so may be more at risk with regard to their online activities. The 'Blocking' of email option on social media can facilitate prevention of unwanted future communications. While students have a wider range of resources they can contact for help compared to the general population, contrary to offline stalking, where ignoring the perpetrator (i.e. non-reinforcing) is advisable.

As anticipated, victims were reluctant to report cyberstalking to authorities because in some cases they failed to identify experiences as cyberstalking and/or as a crime. The findings are in keeping with Spitzberg and Hoobler's [5] assertion that often victims feel the police cannot help. These views need challenging! Cavezza and McEwan [14] argued cyberstalking and offline stalking frequently co-occur though 'pure' cyberstalking is less likely to attract police attention. There may be unknown differences between cyberstalkers who use email only versus those who stalk their victims via social networking sites and the Internet.

Finn [23] reported only $3 \%$ felt reporting it was worthwhile, a figure similar to the present study's 5\%, yet once again male victims were less likely to report the cyberstalking which may be more indicative of 'machismo'. Classmates or ex-intimates were the most likely victims, a finding that seems consistent over time [38].

In the social networking era, it would appear cyberstalking is prevalent among young adults. It is in many ways different from conventional offline stalking, and should be addressed as a possible separate issue because of gender differences and responses to cyberstalking or at least a sub-division. Initially it was felt student samples may be inadequate for a thorough investigation in the light of worldwide accessibility to the Internet. There is always a risk that participants have exaggerated, understated or fabricated their answers, especially where victimisation is concerned and they have an interest in the subject. Females were unintentionally approached more often and students were found in some of the designated offcampus non-student sites. The sample reflected the general population with regards to sexual 
orientation but not on ethnicity, although the higher than general population group allows statistical analysis to be undertaken. Some participants could not ascertain whether numerous experiences had the same perpetrator because the perpetrator's identity was unknown. It is likely that some of these unknowingly met the criteria for cyberstalking victimisation hence additional information would have been valuable. The limitation of the sample size of 100 is recognised. Although there are clear differences between gender and between ethnicity, an area of limited research.

The longer participants had been using the Internet, the more likely they were to be targeted by unknown persons. This is likely to be a logical explanation as there is likely to be a correlation between the years of use and risk of being cyberstalked. Researchers need to be aware that not only are people targeted but many major institutions, see D'Ovidio \& Doyle [19], and organizations by black and white hatted hackers.

There were no significant gender differences in cyberstalking victimisation across groups (14), however, males were significantly more likely to experience somebody attempting to monitor their actions $(\mathrm{p}<0.05)$. Females were more likely to prevent further communication $(\mathrm{p}<0.01)$ and more inclined to try numerous responses. While gender differences could be expected based on the earlier literature, it was surprising that gender response was different in that males ignored it or did not even consider it a major problem compared to females or was it 'macho behaviour' not to treat it as a problem?

The earlier participants began using the Internet and the more they currently used it, the more likely they were to experience problems. While males were more often victims of cyberstalking and females were more likely to be victims of off-line stalking. Cyberstalking victims were more likely to receive threats and cyberstalkers were more likely to threaten suicide. Those who experienced cyberstalking were also likely to experience off-line harassment by the stalker. Mullen et al. [2009] argued that stalking victims often demonstrate presentations consistent with Post Traumatic Stress Disorder, anxiety, depression and substance abuse, while we would argue that the impact of cyberstalking is equally severe. It is not clear how many victims suffered mental health problems including PTSD. Aiken and Berry [39] ironically argue that suffers of PTSD could benefit from treatment in virtual reality.

It could be argued that cyberstalkers with different motivations appear to use the Internet for different purposes, reinforcing the importance of considering motivation when assessing risk and managing cases in mental health and legal settings. In addition, from a behavioural viewpoint clinicians should look at individual reinforcement schedule to evaluate the meaning to the perpetrator rather than necessarily looking at group classification. We agree with Cavezza and McEwan's [14] argument that mental health organisations and the legislature do not need to adopt a different approach when assessing, treating or managing cyberstalkers. The knowledge that ethnic minority females are being cyberstalked by relatives (from a patriarchal centred culture) is worrying yet surely secular societies such as the U.K. should try to stop this practice.

Although we argue that our results can be expanded to cover the UK, we do note that UK regional differences exist, for example the Merseyside region has been identified as having a higher off line average prevalence of stalking [40].

The finding that students are less likely to be cyberstalked than the general public raises an interesting question of whether we should be critical of student population studies. The major implication for the future is to make the Public aware of the risks and actuality of 
cyberstalking, via universities, government adverts and the School National Curriculum. Security needs to be improved in facilities offering public access to the Internet and the Police's reputation needs to be enhanced so that victims are willing to report cyberstalking but most of all individuals need to recogbnise it when it is happening to them.

\section{CONFLICT OF INTEREST}

The authors received no financial support for the research or authorship of this article and have no conflict of interest.

\section{References}

1. Bocij, P. (2004). Cyberstalking: Harassment in the Internet age and how to protect your family, Connecticut, USA: Praeger Publishers.

2. Sheridan, L.P. \& Grant, T. (2007). Is cyberstalking different? Psychology, Crime \& Law, 13(6), 627-640. doi:10.1080/10683160701340528.

3. Pathe, M. \& Mullen, P.E. (1997). The impact of stalkers on their victims. British Journal of Psychiatry, 170, 12-17.

4. Tjaden, P. \& Thoennes, N. (1998). Stalking in America: Findings from the National Violence Against Women Survey. US Department of Justice, Retrieved from http:// www. ncjrs. gov/ pdffiles/169592.pdf.

5. Spitzberg, B.H. \& Hoobler, G. (2002). Cyberstalking and the technologies of interpersonal terrorism. New Media \& Society, 4(1), 71-92. doi: 10.1177/146144402 22226271.

6. Budd, T. \& Mattinson, J. (2000). Stalking: Findings from the 1998 British Crime Survey. London: Home Office. Home Office Research, Retrieved from http://rds. home office. .gov.uk/rds/pdfs/r129.pdf2013/07/14/26c11442-e359-11e2-aef3-339619eab080_ story. html?tid=pm _ local_pop.

7. Dressing, H. Kuehner, C. \& Gass, P. (2005). Lifetime prevalence and impact of stalking in a European population: Epidemiological data from a middle-sized German city. British Journal of Psychiatry, 187, 168-172.

8. Australian Bureau of Statistics. (2013). Personal Safety Survey, Australia. Canberra: Author.http:// www.abs.gov.au/ausstats/abs@.nsf/mf/4906.0.

9. Mullen, P.E. Pathe, M. \& Purcell, R. (2009). Stalkers and their Victims (2nd), Cambridge, UK: Cambridge University Press.

10. Swedish National Council for Crime Prevention. (2006). Stalking in Sweden. Prevalence and prevention. Stockholm: Author.

11. Smith, K.E., Coleman, K., Eder, S., \& Hall, P. (2011). Homicides, firearms offences and intimate violence 2009/10, Home Office Statistical Bulletin. London: Home Office.

12. Baum, K., Catalano, S., Rand, M., \& Rose, K. (2009). Stalking victimization in the United States. Washington, DC: US Department of Justice.

13. Parsons-Pollard, N., \& Moriarty, L.J. (2009). Cyberstalking: Utilizing what we do know. Victims \& Offenders, 4, 435-441. doi:10.1080/15564880903227644.

14. Cavezza, C. \& McEwan, T.E. (2014) Cyberstalking versus off-line stalking in a forensic sample, Psychology, Crime \& Law, 20:10, 955-970, doi:10.1080/1068316X. 2014.893334.

15. Grabosky, P. (2001). Virtual criminality: Old wine in new bottles? Social and Legal Studies, 10(2), 243249.

16. Bocij, P. \& MacFarlane, L. (2003, 1 September). An exploration of predatory behaviour in cyberspace: Towards a typology of cyberstalkers. First Monday, 8(9). http://firstmonday.org/htbin/cgiwrap/bin/ojs/index.php/fm/article/view/1076/996.

17. Dreßing, H., Bailer, J., Anders, A., Wagner, H., \& Gallas, C. (2014). Cyberstalking in a Large Sample of Social Network Users: Prevalence, Characteristics, and Impact upon Victims. Cyberpsychology, Behavior, and Social Networking, 17(2), 61-7. 
18. Kodellas, S., Giannakoulopoulos, A. \& Floros, A. (2010). Cyberstalking victimisation: The role of online lifestyles and routine activities, (In the proceedings of WebSci10: Extending the frontiers of society online). http://journal.web science .org/ 380/.

19. D'Ovidio, R. \& Doyle, J. (2003). A study on cyberstalking: Understanding investigative hurdles. FBI Law Enforcement Bulletin, 72(3), 10-17.

20. Crime Survey for England \& Wales (2017). www.crimesurvey.co.uk/SurveyResults.htm.

21. Bocij, P. (2003). Victims of cyberstalking: An exploratory study of harassment perpetrated via the Internet. First Monday, 8(10) Retrieved from http://first monday.org /htbin /cgi wrap/ bin/ojs/index.php/fm/article/view /1086/1006.

22. Bocij, P. \& MacFarlane, L. (2002). Online harassment: Towards a definition of cyberstalking. Prison Service Journal, 139, 31-38.

23. Finn, J. (2004). A survey of online harassment at a university campus. Journal of Interpersonal Violence, 19(4). 468-483. doi:10.1177/0886260503262083.

24. Alexy, E.M., Burgess, A.W., Baker, T. \& Smoyak, S.A. (2005). Perceptions of cyberstalking among college students. Brief Treatment and Crisis Intervention, 5 (3) 279-289.doi:10. 1093/brieftreatment/mhi020.

25. Maple, C., Short, E., \& Brown, A. (2011). Cyberstalking in the United Kingdom. An analysis of the ECHO pilot survey. Luton, England: National Centre for Cyberstalking Research, University of Bedfordshire.

26. McEwan, T.E., Mullen, P.E., MacKenzie, R., \& Ogloff, J.R.P. (2009). Violence in stalking situations. Psychological Medicine, 39, 1469-1478. doi:10.1017/S00332917 08004996.

27. Nobles, M.R., Reyns, B.W., Fox, K.A., \& Fisher, B.S. (2012). Protection against pursuit: A conceptual and empirical comparison of cyberstalking and stalking victimization among a national sample. Justice Quarterly, 1-29. Retrieved from http://dx.doi:10.10 80/07418825. 2012.723030.

28. Spitzberg, B.H., \& Cupach, W.R. (2007). The state of the art of stalking. Taking stock of the emerging literature. Aggression and Violent Behaviour: A Review Journal, 12, 64-86. doi:10. 1016/j.avb.2006.05.001.

29. Strand, S., \& McEwan, T.E. (2012). Violence among female stalkers. Psychological Medicine: A Journal of Research in Psychiatry and the Allied Sciences, 42, 545-555. doi: 10.1017/S0033291711001498.

30. Suler, J. (2004). The online disinhibition effect. CyberPsychology and Behaviour, 7, 321-327. doi:10.1089/1094931041291295.

31. Roberts, L. (2008). Jurisdictional and definitional concerns with computer-mediated interpersonal crimes: An analysis on cyber stalking. International Journal of Cyber Criminology, 2(1). 271-285.

32. Ménard, K.S., \& Pincus, A.L. (2012). Predicting overt and cyber stalking perpetration by male and female college students. Journal of Interpersonal Violence, 27, 2183-2207. doi: 10.1177/0886260511432144.

33. Berry, M.J. (2017). Being Deaf in Mainstream Education in the United Kingdom: Some Implications for their Health, Universal Journal of Psychology 5(3): 129-139, 2017 DOI: 10.13189/ujp.2017.050305.

34. Paullet, K.L. Rota, D.R. \& Swan, T.T. (2009). Cyberstalking: An exploratory study of students at a MidAtlantic university. Issues in Information Systems, X (2), 640-649.

35. Flesch, R. (1948). A new readability yardstick. Journal of Applied Psychology, 32: 221-233. doi: $10.1037 / h 0057532$.

36. Corporate Research and Intelligence. (2009). Derived Population Projections by Ward. Retrieved from http://www.manchester.gov.uk/downloads/download/4220/corporate_research_and_intelligence_popu lation_publications.

37. WHOA. (2009). Online harassment statistics. Retrieved from http://www.haltabuse.org/resources/stats/index.shtml.

38. Hammond, L., Ioannou, M. \& Percival, H. (2016). Cyberstalking Public Perception and Experiences, paper presented at the BPS Division of Forensic Psychology Annual Conference, Brighton, June, 2016.

39. Aiken, M. \& Berry, M. J. (2015). Post-traumatic Stress Disorder: Possibilities for Olfaction and Virtual Reality Exposure Therapy, Virtual Reality, 19:95-109. doi:10.1007/s10055 055 -015-0260-x.

40. Liverpool Echo (2016). Merseyside is still the stalking capital of England and Wales by Joe Thomas \& Rob Grant, 11 $11^{\text {th }}$ September, 2016. 